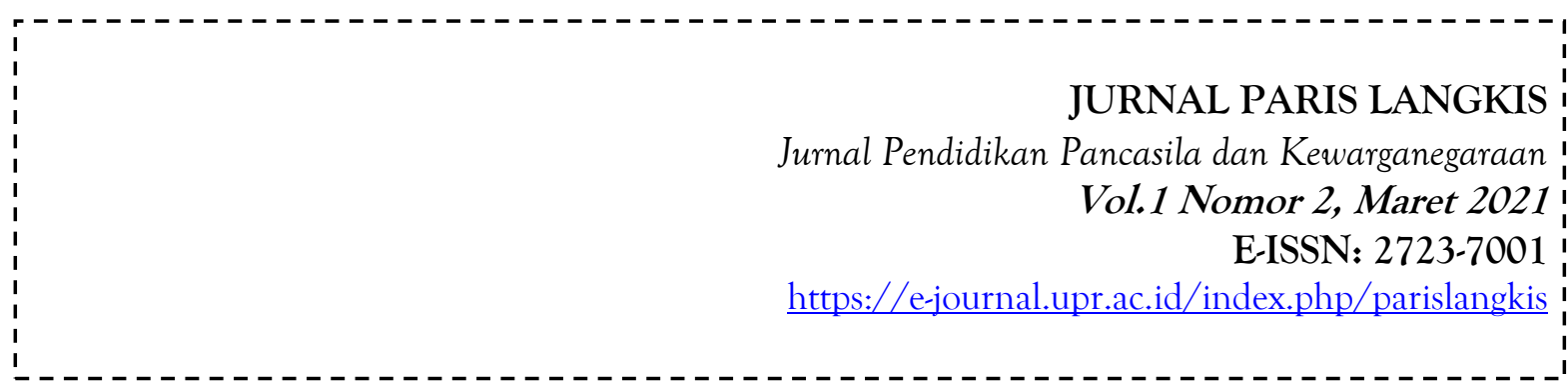

\title{
PERSPEKTIF MAHASISWI PRODI PPKn UNIVERSITAS PALANGKA RAYA TETANG BUDAYA POPULER KOREA (K-POP) TERHADAP GAYA HIDUP
}

\author{
Ledy Femina Sitanggang ${ }^{1}$, Eddy Lion ${ }^{2}$, Offeny ${ }^{3}$ \\ ${ }^{1,2,3}$ Prodi PPKn, Universitas Palangka Raya \\ Email:ledyfeminasitanggang07@gmail.com ${ }^{1}, e d d y @ y a h o o . c o m^{2}$,offeny.pky58@gmail.com³
}

\begin{abstract}
Abstrak :
Penelitian ini dilakukan untuk mengetahui bagaimana Perpektif para mahasiswi Program Studi PPKn tentang budaya populer korea (K-Pop) terhadap gaya hidup serta mendeskripsikan dan menganalisis faktor pendukung dan penghambat para mahasiswi Program Studi PPKn menggemari budaya populer korea (K-Pop) tersebut. Metode yang digunakan dalam penelitian ini meliputi: Observasi,wawancara dan dokumentasi. Sumber data pada penelitian ini sumber data Primer subyek penelitian diambil berdasarkan Purposive samplingdan sumber data sekunder.Berdasarkan hasil penelitian dan pembahasan dapat disimpulkan bahwa bentuk gaya hidup para mahasiswi dari menggemari budaya populer korea adalah pertama mahasiswi yang tinggal di barak bentuk gaya hidup Public Relation dan Journalism gaya hidup dan gaya hidup hedonis, kedua mahasiswi yang tinggal dengan orang tua bentuk gaya hidup hedonis dan iklan gaya hidup, ketiga mahasiswi asli daerah bentuk gaya hidup Public Relation dan Journalism gaya hidup dan gaya hidup hedonis, keempat Mahasiswi Program Studi PPKn angkatan 2016 bentuk gaya hidup hedonis dan iklan gaya hidup, kelima mahasiswi Program Studi PPKn angkatan 2017 bentuk gaya hidup hedonis dan iklan gaya hidup. Faktor Pendukung mahasiswi Program Studi PPKn menggemari budaya populer korea (K-Pop) adalah Perkembangan Teknologi, Media Massa, Lingkungan Pertemanan, serta Visual dan bakat artis-artis Korea. Sedangkan Faktor Penghambat para mahasiswi Program Studi PPKn dalam menggemari budaya populer korea (K-Pop) adalah Pertama Mahasiswi yang tinggal di barak faktor penghambatnya adalah finansial/keuangan dan lingkungan sekitar mahasiswi, kedua mahasiswi yangtinggal bersama dengan orang tua faktor penghambatnya adalah larangan orang tua untuk tidak menggemari budaya populer
\end{abstract}

Paris Langkis

Vol.1 Nomor 2, Maret 2021 
korea (K-Pop), ketiga Mahasiswi Asli daerah faktor penghambatnya adalah Keuangan dan perbedaan budaya, keempat mahasiswi Program Studi PPKn angkatan 2016 faktor penghambatnya adalah Keuangan dan keuangan dan perbedaan budaya, kelima Mahasiswi Program Studi PPKn angkatan 2017 faktor penghambatnya adalah perbedaan kebudayaan dan Lingkungan Sekitar Mahasiswi.

Kata kunci : Budaya populer Korea (K-Pop), Gaya Hidup

\section{Abstract:}

This research was conducted to find out how the perspective of the PPKn Study Program students on Korean popular culture (K-Pop) on lifestyle and to describe and analyze the supporting and inhibiting factors of the PPKn Study Program students who like Korean popular culture (K-Pop). The methods used in this research include: observation, interviews and documentation. The data source in this study was the primary data source of the research subjects taken based on purposive sampling and secondary data sources. Based on the results of research and discussion, it can be concluded that the form of the student's lifestyle from favoring Korean popular culture is thefirst female student who lives in the barracks, the form of the Public Relations and Journalism lifestyle, hedonic lifestyle and lifestyle, the two students who live with parents form a hedonistic lifestyle. and lifestyle advertisements, the three students who are native to the region form a Public Relations and Journalism lifestyle and a hedonistic lifestyle, the four students of the 2016 PPKn Study Program form a hedonistic lifestyle and lifestyle ads, the five students of the 2017 PPKn Study Program form a hedonistic lifestyle and lifestyle advertising. Supporting factors for students of the PPKn Study Program who are fond of Korean popular culture (KPop) are the development of technology, mass media, friendship environment, as well as visuals and talents of Korean artists. While the Inhibiting Factors of the PPKn Study Program students in favoring Korean popular culture (K-Pop) areFirst Students who live in barracks, the inhibiting factor is financial / financial and the environment around the student, the two students who live together with their parents the inhibiting factor is the prohibition of parents to do not like Korean popular culture (K-Pop), the three native students of the region the inhibiting factors are finance and cultural differences, the four students of the 2016 PPKn Study Program the inhibiting factors are finance and finance and cultural differences, the five students of the 2017 PPKn Study Program the inhibiting factors are differences in culture and the environment around students.

Key words: Korean popular culture (K-Pop), Lifestyle

\section{A. PENDAHULUAN}

Saat ini perkembangan zaman semakin hari semakin modern diiringi dengan perkembangan Teknologi yang semakin pesat. Perkembangan teknologi informasi khususnya media

\section{Paris Langkis}

Vol.1 Nomor 2, Maret 2021 
massa memberikan dampak yang sangat besar dalam kemajuan komunikasi. Teknologi informasi dan peran serta media mendorong munculnya budaya-budaya yang disukai oleh banyak orang di seluruh dunia. Budaya yang disukai secara luas oleh banyak orang disebut budaya populer, budaya pop/popular culture, atau budaya massa/mass culture Budaya ini mencakup seluruh praktik kehidupan sehari-hari, mulai dari memasak, gaya berpakaian, olahraga, dunia hiburan, dll.

Penyebaran informasi pada media massa saat ini berkaitan dengan budaya populer. Bungin "Secara sosiologis merupakan budaya yang sedang tren, diminati, budaya populer biasanya berkaitan dengan masalah keseharian yang dapat dinikmati oleh semua orang atau kalangan tertentu,seperti musik, film, fashion, dan lain-lain" (Ida Ri'aeni et al., 2019:2)

Salah satu budaya yang tengah mempengaruhi berbagai negara adalah budaya pop Korea atau yang lebih dikenal dengan sebutan K-pop/Hallyu Wave/Korean Wave. Belakangan ini budaya Korea Populer (K-Pop) begitu mewabah dikalangan para anak-anak muda di Indonesia termasuk anak-anak muda di kota palangka raya khususnya di lingkungan Universitas Palangka Raya. Korea Populer (K-Pop) bukan dikenal hanya sekedar musik tetapi semua budaya tentang korea selatan.

Sun Jung juga mengatakan bahwa "pada awal kemunculan Korean Wave di Asia, gaya hidup menjadi dasar bagi munculnya budaya Asia yang dikonstruksikan pada fase pengembangan perekonomian dan teknologi sebagai peningkatan jumlah konsumen produk" (Ridaryanthi, 2014:93)

Gaya hidup para penggemar budaya korea (K-Pop) biasanya mengikuti gaya hidup para idolanya, maupun budaya korea itu sendiri. Dimulai dengan menikmati semua produk korea selatan seperti fim, musik, drama, fashion, dan makanan khas dari Negara gingseng tersebut. maka fokus pada penelitian ini adalah untuk mencari tau tentang bagaimana sudut pandang mereka terhadap budaya populer Korea dan gaya hidup yang di timbulkan oleh menggemari budaya Populer Korea tersebut serta mendeskripsikan dan menganalisis faktor pendukung dan penghabat mahasiswi prodi PPkn menggemari budaya populer korea (K-Pop) tersebut.

\section{B. KAJIAN TEORI}

Roger M. Keesing mengatakan (Keesing, 2014:3) "Budaya adalah sistem (dari polapola tingkah laku diturunkan secara sosial) yang bekerja menghubungkan komunitas manusia dengan lingkungan ekologi mereka. Dalam "cara hidup komuniti" ini termasuklah

\section{Paris Langkis}

Vol.1 Nomor 2, Maret 2021 
teknologi dalam bentuk organisasi ekonomi, pola-pola menetap, bentuk pengelompokan sosial dan organisasi politik, kepercayaan dan praktek keagamaan, dan seterusnya.Bila budaya dipandang secara luas sebagai sistem tingkah laku yang khas dari suatu penduduk, satu penyambung dan penyelaras kondisi-kondisi badaniah manusia".

Dalam KBBI populer memiliki arti "dikenal dan disukai orang banyak (umum), sesuai dengan kebutuhan masyarakat pada umumnya; mudah di pahami orang banyak dan disukai dan dikagumi orang banyak".

Tressia (Aslamiyah 2013:18) Istilah "budaya Populer" ( culture popular) sendiri dalam bahasa latin merujuk secara harafiah pada "culture of the people" ( budaya orang-orang atau masyarakat). Titi Nur Vidiarini (Titi Nur Vidyarini, 2008:53) mengatakan : "Budaya populer tidak ada begitu saja, budaya populer ada karena suatu hal yang awalnya biasa saja menjadi sebuah fenomena populer. Budaya-hasil cipta, rasa, karsa manusia-menjadi budaya populer ketika ia memenuhi beberapa ciri, yaitu (1) Tren, sebuah budaya yang menjadi trend dan diikuti atau disukai banyak orang berpotensi menjadi budaya populer; (2) Keseragaman bentuk, sebuah ciptaan manusia yang menjadi tren akhirnya diikuti oleh banyak copycatpenjiplak. Karya tersebut dapat menjadi pionir bagi karya-karya lain yang berciri sama, sebagai contoh genre musik pop (diambil dari kata popular) adalah genre musik yang notasi nada tidak terlalu kompleks, lirik lagunya sederhana dan mudah diingat; (3) Adaptabilitas, sebuah budaya populer mudah dinikmati dan diadopsi oleh khalayak, hal ini mengarah pada tren; (4) Durabilitas, sebuah budaya populer akan dilihat berdasarkan durabilitas menghadapi waktu, pionir budaya populer yang dapat mempertahankan dirinya bila pesaing yang kemudian muncul tidak dapat menyaingi keunikan dirinya, akan bertahan-seperti merek Coca-cola yang sudah ada berpuluh-puluh tahun; (5) Profitabilitas, dari sisi ekonomi, budaya populer berpotensi menghasilkan keuntungan yang besar bagi industri yang mendukungnya”.

Salah satu budaya populer yang sedang di gemari di berbagai Negara adalah budaya populer korea (K-Pop). Korea Selatan pada beberapa tahun terakhir ini berhasil menyebarkan produk budaya populernya ke dunia internasional. Berbagai produk budaya Korea mulai dari drama film, lagu, fashion, gaya hidup produk-produk industri mulai mewarnai kehidupan masyarakat di berbagai belahan dunia. Budaya Korea berkembang begitu pesatnya dan meluas serta diterima publik sampai menghasilkan sebuah fenomena demam Korean Wave.

Definisi gaya hidup itu sendiri dikemukakan oleh Plummer (Kaparang, 2013:3). "Gaya hidup adalah cara hidup individu yang di identifikasikan oleh bagaimana orang

\section{Paris Langkis}

Vol.1 Nomor 2, Maret 2021 
menghabiskan waktu mereka (aktivitas), apa yang mereka anggap penting dalam hidupnya (ketertarikan) dan apa yang mereka pikirkan tentang dunia sekitarnya." Jadi, gaya hidup dapat dikatakan sebagai suatu pola hidup seseorang di dunia yang diekspresikan dalam aktifitas, minat, dan opininya.

Gaya hidup ala K-Pop sedang banyak di gemari oleh kalangan mahasiswi saat ini. Gaya hidup merupakan salah satu bentuk dari budaya yang dapat kita temui dalam kehidupan kita sehari-hari, karena gaya hidup merupakan bagian dari diri manusia yang bisa menunjukkan siapa dirinya dan identitas dirinya. Hal ini dipengaruhi beberapa faktor seperti musik, drama, fashion dan film asal korea selatan sehingga mereka mulai menyukai hal-hal yang berbaur korea dan juga menyebabkan makin bertambahnya para penyuka Budaya Populer Korea (KPop). Hal ini yang menyebabkan budaya populer korea sangat di gandrungi oleh para mahasiswa.

\section{METODE PENELITIAN}

Penelitian ini menggunakan pendekatan kualitatif yakni prosedur penelitian yang menghasilkan data-data deskriptif berupa kata-kata tertulis atau lisan dari orang-orang dan perilaku yang diamati.Selain itu, data-data yang dikumpulkan di lapangan adalah data yang berbentuk kata dan perilaku, kalimat, skema, gambar dengan latar belakang alamiah, dan manusia sebagai instrumennya.

Metode penelitian kualitatif menekankan pada metode penelitian observasi dan dialog (wawancara mendalam) di lapangan dan datanya dianalisa. dengan cara non-statistik. Pendekatan kualitatif menekankan pada makna dan pemahaman dari dalam (verstehen), penalaran, definisi suatu situasi tertentu (dalam konteks tertentu), lebih banyak meneliti halhal yang berhubungan dengan kehidupan sehari-hari. Pendekatan kualitatif lebih mementingkan pada proses dibandingkan dengan hasil akhir; oleh karena itu urut-urutan kegiatan dapat berubah-ubah tergantung pada kondisi dan banyaknya gejala-gejala yang ditemukan. Tempat penelitian yang akan dilakukan di Prodi PPKn Universitas Palangka Raya yang beralamat di jalan Jl. B. Koetin, Palangka, Kec. Jekan Raya, Kota Palangka Raya, Kalimantan Tengah 74874.

Adapun sumber data yang di peroleh adalah (1) sumber data primer adalah sumber data yang memberikan data langsung dalam penelitian ini.

Paris Langkis

Vol.1 Nomor 2, Maret 2021 
Sumber datanya di ambil berdasarkan Purposive Sampling.Purposive Sampling adalah teknik pengambilan sampel sumber data dengan pertimbangan tertentu, misalnya sumber datanya adalah orang yang dianggap tahu tentang apa yang diharapkan, atau dengan kata lain pengambilan sumber data/informan sesuai dengan kebutuhan peneliti. Adapun narasumber dalam penelitian adalah :

Mahasiswi Program Studi PPKn yang tinggal di barak berjumlah 2 orang, Mahasiswi Program Studi PPkn yang tinggal bersama orang tua berjumlah 2 orang, Mahasiswi Program Studi PPKn asli daerah berjumlah 2 orang, Mahasiswi Program Studi PPKn angkatan 2016 berjumlah 2 orang, Mahasiswi Program Studi PPKn angkatan 2017 berjumlah 2 orang jumlah subyek penelitian ada 10 mahasiswi Program Studi PPKn

(2) sumber data sekunder. Sumber data sekunder adalah data yang di peroleh dari data-data yang sudah ada seperti penelitian terdahulu, internet, dan berbagai jurnal.

Adapun teknik pengumpulan data yang akan di gunakan dalam penelitian ini adalah sebagai berikut :

Observasi Menurut Sugiyono (Absari ,2013:47) observasi adalah metode pengumpulan data dimana penyelidik mengadakan pengamatan secara langsung terhadap suatu benda, kondisi atau situasi, proses dan perilaku.

Wawancara/interview adalah teknik yang di laksanakan dengan cara dialog baik secara langsung (tatap muka) maupun melalui saluran media tertentu antara pewara dengan yang di wawancarai sebagai sumber data

Dokumentasi Langkah terakhir dalam melakukan pengumpulan data dengan metode dokumentasi mengenai profil responden dan juga hasil observasi secara langsung, seperti dokumen pribadi, dokumen resmi, referensi- referensi, foto-foto yang menunjang penelitian dan rekaman wawancara tentang kondisi lapangan tersebut. Yaitu mahasiswi yang menjadi subjek penelitian.

Analisis data adalah proses mencari dan menyusun secara sistematis data yang diperoleh dari hasil wawancara, catatan lapangan, dan dokumentasi, dengan cara mengorganisasikan dalam kategori, menjabarkan kedalam unit-unit, melakukan sintesa, menyusun kedalam pola, memilih mana yang penting dan yang akan di pelajari, dan membuat kesimpulan sehingga mudah di pahami oleh diri sendiri dan orang lain.

\section{Paris Langkis}

Vol.1 Nomor 2, Maret 2021 
Analisis data terdiri dari tiga alur kegiatan yang terjadi secara bersamaan yaitu: reduksi data, penyajian data, dan penarikan kesimpulan/ verifikasi.

\section{D.HASIL PENELITIAN}

Setelah melakukan penelitian dan pengumpulan data dari hasil penelitian yang diperoleh melalui Observasi, wawancara,dan dokumentasi maka selanjutnya peneliti akan menganalisis data dari hasil penelitian terhadap mahasisiwi Program Studi PPKn Universitas Palangka Raya. Adapun hasil analisis dari hasil penelitian ini adalah sebagai berikut.

1. Perspektif mahasiswi Program Studi PPKn Universitas Palangka Raya tentang budaya populer korea terhadap gaya hidup.

Budaya populer korea (K-Pop) telah suskes menarik perhatian kaum muda terkususnya para kaum wanita di indonesia. Terbukti dari tanggapan mahasiswi yang menerima dan terbuka terhadap budaya populer korea (K-Pop). Budaya populer korea ini dianggap menarik perhatian karena budayanya yang berbeda dengan budaya populer pada umumnya. Budaya populer Korea (K-Pop) ini mampu menciptakan ciri khas/ citra yang tidak dimiliki budaya lainnya.

Budaya Populer korea (K-Pop) diminati para mahasiswi Program Studi PPKn dengan beberapa alasan yakni. 1) Musik korea dianggap menarik karena memiliki ciri khas mereka sendiri, jenis musik yang ditayangkan berbeda dari konsep musik populer lainnya. Boyband dan girlband menjadi ikon dari musik korea ini, perpaduan musik beat dan gerakan dance yang energik adalah ciri khas musik budaya populer Korea (K-Pop) 2) Drama korea, hal yang menjadi daya tarik para mahasiswi Program Studi PPKn menggemari drama dari budaya populer korea (K-Pop) ini adalah konsep yang ditawarkan menarik, berbeda dari konsep yang sering di jumpai di drama/sinetron Indonesia. Dalam drama korea alur cerita dibuat seringkas mungkin, sedangkan drama Indonesia yang memiliki alur cerita yang panjang dan bertele-tele menjadikan para mahasiswi lebih memilih untuk menggemari drama dari budaya populer korea (K-Pop).

3) Variety Show, tayangan ini mampu menarik perhatian para mahasiswi Program Studi PPKn karena dianggap sangat menghibur. Tayangan yang disuguhkan adalah tayangan-tayangan lucu, konsep yang berbeda disetiap episode membuat para mahasiswi untuk menantikan tayangan ini. 4) Budaya makan korea dianggap menarik karena cara makan dan makanannya yang berbeda dengan Indonesia. Korea selatan dalam menyantap makanannya menggunakan sumpit dan dengan lauk yang banyak

\section{Paris Langkis}

Vol.1 Nomor 2, Maret 2021 
dan berbeda-beda, beda halnya dengan Indonesia yang terbiasa makan dengan menggunakan tangan/ sendok. Jika diperhatikan sumpit digunakan dalam menyantap jenis makanan apapun, hal ini menjadikan para mahasiswi ingin lebih tau dengan budaya ini.

Budaya populer Korea ini menjadi budaya yang dicontoh para mahasiswi Program Studi PPKn dalam kehidupan sehari-hari terbuti dari hasil wawancara dan Observasi yang dilakukan terhadap para mahasiwi Program Studi PPKn yang cenderung mengikuit gaya hidup para orang korea.

Berikut adalah gaya hidup para mahasiswi yang menggemari budaya populer korea (K-Pop).

Pertama Mahasiswi yang tinggal dibarak, gaya hidup yang dijalani sehari-hari akibat menggemari budaya populer korea (K-Pop) adalah menghabiskan waktu luangnya untuk menonton dan mendengarkan musik, drama dan variety Show korea dari berbagai media sosial seperti Youtube, Instagram, Facebook dan media sosial lainnya , para mahasiswi yang tinggal dibarak juga mengikuti sedikit trend berpakaian korea, mereka mengikuti sebagian cara berpakain para artis korea seperti jenis celana/rok sepatu, aksesoris dan cara memadu pandankannya .

Dari data diatas maka ditemukan bahwa bentuk gaya hidup para Mahasiswi yang tinggal di barak adalah Public Relation dan jurnalisme gaya hidup dimana mahasiswi yang tinggal dibarak mengikuti sebagian penampilan dari tren populer korea yang menjadi gaya hidupnya sehari-hari. Mahasiswi menjadikan para artis korea sebagai panutan dalam berbusana. Kemudian bentuk gaya hidup Hedonis, gaya hidup dari suatu penampilan melalui media iklan, modeling dan artis yang di idolakan. Para mahasiswi yang tinggal di barak menghabiskan waktu unutk menikmati dan mengikuti hasil budaya populer korea yang dibintangi oleh artis/idol yang disukainya. Jadi bentuk gaya hidup mahasiswi yang tinggal dibarak adalah industry gaya hidup dan gaya hidup hedonis.

KeduaMahasiswi yang tinggal dengan orang tua, dari penjelasan para mahasiswi yang tinggal dengan orang tua dapat disimpulkan bahwa mereka tidak terlalu mengikuti cara berpakaian/trend Fashion korea tapi dalam menghabiskan waktu luangnya disela kesibukan kampus dan pekerjaan di rumah untuk menikmati hasil dari budaya populer korea (K-Pop) mulai dari menonton drama- dramanya, mendengarkan musik serta mengikuti perkembangan para artis yang digemari melalui media sosial, serta dalam menghabiskan uangnya untuk membeli beberapa produk makanan dan minuman lokal yang dibintangi oleh para artis/idol korea.

\section{Paris Langkis}

Vol.1 Nomor 2, Maret 2021 
Dari data yang didapatkan diatas maka dapat disimpulkan bentuk gaya hidup mahasiswi yang tinggal dengan orang tua adalah gaya hidup hedonis, para mahasiswi yang tinggal bersama orang tua menghabiskan waktu luangnya untuk menonton dan mendengarkan musik dan drama dari budaya populer korea sebagai hiburan. Kemudian iklan gaya hidup para mahasiswi menggunakan uangnya untuk membeli produk-produk yang di bintangi oleh para artis idolanya. Maka bentuk gaya hidup mahasiswi yang tinggal dengan orang tua adalah gaya hidup Hedonis dan iklan gaya hidup.

KetigaMahasiswi asli daerah, gaya hidup yang dimiliki oleh mahasiswi asli daerah dari menggemari budaya populer korea (K-Pop) adalah Mereka mengikuti beberapa trend dari para artis korea, mulai dari meluangkan waktu menikmati tayangan budaya populer korea (K-Pop) baik drama maupun musik, mengikuti trend fashion, menggunakan penggalan kata korea. Mengoleksi beberara album dan poster dari artis kesukaanya. Kemudian dijelaskan juga bahwasanya gaya hidup nya menjadi tinggi akibat menggemari budaya populer korea (K-Pop)

Bentuk gaya hidup mahasiswi Asli daerah dari hasil wawancara langsung maka dapat disimpulkan Bentuk gaya hidup mahasiswi Asli daerah dari hasil wawancara langsung maka dapat disimpulkan bentuk gaya hidupnya akibat menggemari budaya populer korea adalah Public Relation dan Journalisme gaya hidup dimana mahasiswi mengikuti tren fashion dari artis korea,kemudian gaya hidup hedonis dimana mahasiswi menjadikan tayangan budaya korea menjadi salah satu hiburan dan cara menghabiskan waktu mereka untuk menikmati tayangan hasil budaya korea.

KeempatMahasiswi Program Studi PPKn angkatan 2016, gaya hidup yang ditimbulkan dari menggemari budaya populer korea adalah penggunaan waktu luang untuk menonton dan mendengar kan musik dan drama korea. Mereka juga terkadang membeli beberapa produk korea atau pun produk lokal/ produksi dalam negeri yang dibintangi atau di promosikan oleh artis K-Pop. Akibat menonton dan mendengarkan musik dan drama yang menggunakan bahasa korea, mereka jadi terbiasa menggunakan penggalan bahasa dalam kehidupan sehari-hari.

Dari data diatas maka dapat ditarik kesimpulan bahwa bentuk gaya hidup yang dijalani para mahasiswi angkatan 2016 adalah gaya hidup hedonis, mereka menghabiskan waktu luang untuk lebih menikmati budaya populer korea mulai dari menonton,mendengarkan musik serta menggunakan media sosial. Lalu Iklan Gaya hidup, para mahasiswi tertarik membeli produk yang dibintangi oleh para artis idolanya.

\section{Paris Langkis}


Kelima Mahasiswi Program Studi PPKn angkatan 2017, mereka menghabiskan waktu luangnya untuk menonton dan mendegarkan musik dan drama korea, mengikuti perkembangan para idol/ artis kesukaannya melalui media sosial. Mereka juga kerap membeli makanan dan minuman produk korea serta tertarik untuk mengunjungi rumah makan yang menyediakan makanan khas korea.

Bentuk gaya hidup mahasiswi angkatan 2017 akibat menggemari budaya populer korea adalah gaya hidup hedonis dan iklan gaya hidup karena mulai tertarik untuk mengonsumsi budaya populer korea (K-Pop).

2. Faktor pendukung dan penghambat yang menyebabkan para mahasiswi Program Studi PPKn menggemari budaya populer Korea

Mahasiswi Program Studi PPKn dalam menggemari budaya populer korea memiliki faktor yang menjadi pendukung untuk menggemari budaya populer Korea (K-Pop) . Berdasarkan temuan penelitian maka faktor pendukung dan penghambat para mahasiswi Program Studi PPKn menggemari budaya populer korea (K-Pop) adalah sebagai berikut.

a. Faktor Pendukung

Dari hasil wawancara dengan 10 Mahasiswi Program Studi PPKn Maka dapat disimpulkan Faktor pendukung para mahasiswi dalam menggemari budaya populer korea (K-Pop). 1) kecanggihan teknologi yang memudahkan para mahasis- wi untuk menikmati tayangan-tayangan budaya populer korea .2) media sosial, Media Sosial yang memberikan informasi dan perkembangan dari budaya populer korea (K-Pop), aplikasi-aplikasi media sosial sebagai sarana para mahasiswi unutuk mengikuti budaya korea (K-Pop). 3) Lingkungan pertemanan, ajakan para mahasiswi penggemar budaya populer korea (K-Pop) kepada mahasiswi yang tidak menggemari yang memperkenalkan hasil budaya korea seperti drama,film dan musiknya sehingga terpengaruh untuk mengikutinya 4) artis-artis korea, korea selatan terkenal dengan visual/ kecantikan para artisnya, wajah yang rupawan, kulit putih dan postur badan yang bagus menjadikan para mahasiswi tertarik untuk mengikuti budaya populer korea (K-Pop).

b. Faktor penghambat para mahasiswi Program Studi PPKn untuk menggemari budaya populer korea (K-Pop).

Pertama Bagi Mahasiswi yang tinggal di barak faktor Penghambatnya adalah finansial/keuangan karena tidak leluasa dalam mendapatkan kebutuhan untuk menikmati budaya populer korea (K-Pop) tersebut, kemudian lingkungan Sekitar

\section{Paris Langkis}

Vol.1 Nomor 2, Maret 2021 
karena perbedaan pandangan yang dimiliki oleh orang-orang sekitar yang tidak menyukai budaya populer korea. hal tersebut membuat para mahasiswi enggan untuk menunjukkan ketertarikannya

Kedua Bagi mahasiswi yang tinggal dengan orang tuanya faktor penghambatnya adalah faktor penghambatnya adalah larangan orang tua untuk tidak menggemari budaya korea karena dianggap mengganggu proses kuliah para mahasiswi.

Ketiga Bagi mahasiswi Asli daerah faktor penghambatnya adalah keuangan, untuk mencapai segala kebutuhan dalam menggemari budaya populer korea (K-Pop) memerlukan dana, sedangkan para mahasiswi

masih mengandalankan orang tua. Kemudian perbedaan kebudayaan dengan korea mengakibatkan kendala bagi mahasiswi untuk menggemari budaya tersebut.

Keempat Bagi mahasiswi Program Studi PPKn angkatan 2016 penghambatnya adalah keuangan para mahasiswi tidak leluasa dalam mengikuti segala hal tentang korea, mulai dari paket data untuk mengakses media sosial,serta keinginan untuk meniru fashion mereka. Kemudian faktor budaya, perbedaan budaya korea dan Indonesia yang membuat para mahasiswi dalam menggemari budaya ini.

Kelima Bagi mahasiswi Program Studi PPKn angkatan 2017 perbedaan budaya antara Indonesia dan korea sehingga para mahasiswi mengalami kendala untuk menerapkan maupun mengikuti kebudayaan mereka . Serta lingkungan sekitar/pertemanan pandangan orang disekitar mahasiswi penggemar budaya populer yang kurang menyenangi budaya korea. Hal ini mengakibatkan para mahasiswi enggan untuk menunjukan ketertarikannya dengan budaya populer korea (K-Pop).

\section{E. SIMPULAN DAN SARAN}

\section{Kesimpulan}

Berdasarkan hasil penelitian dan pembahasan maka dapat disimpulkan budaya perspektif mahasiswi Program Studi PPKn Universitas Palangka Raya tentang budaya populer korea (K-Pop), mahasiswi Program Studi PPKn menganggap budaya populer korea adalah sesuatu yang menarik, karena budaya yang ditampilkan berbeda dari budaya populer pada umumnya. Budaya korea menciptakan citra mereka sendiri baik dalam hal musik, drama, dan budaya yang lainnya.

Budaya Populer korea (K-Pop) sangat disukai para maahsiswi karena cocok dengan seleranya. Pendapat para mahasiswi yang disampaikan pada saat wawancara tentang hal yang

Paris Langkis

Vol.1 Nomor 2, Maret 2021 
menjadi daya tarik dari budaya populer korea (K-Pop) ini yakni.1) musiknya yang berbeda dari yang biasa dijumpai 2) Drama korea 3) Variety show yang menampikan tayangan yang mampu menghibur para penontonnya.

Adapun pengaruh budaya populer korea (K-Pop) terhadap gaya hidup para mahasiswi yang menggemari budaya populer korea (K-Pop) adalah 1) bentuk gaya hidup mahasiswi Program Studi PPKn yang tinggal di barak adalah Public Relation dan journalisme gaya hidup karena mahasiswi mengikuti trend fashion para artis-artis korea dan gaya hidup Hedonis karena menghabiskan waktu unutk menikmati dan mengikuti hasil budaya populer korea yang dibintangi oleh artis/idol yang disukainya. 2) mahasiswi yang tinggal dengan orang tua bentuk gaya hidupnya adalah gaya hidup hedonis, menghabiskan waktu luangnnya unutk menikmati hasil dari budaya populer korea.rambut serta warna rabut para mahasiswi megikuti warna dan gaya para artis korea. Kemudian iklan gaya hidup para mahasiswi menggunakan uangnya untuk membeli produk-produk yang di bintangi oleh para artis idolanya.

3)bentuk gaya hidup Para mahasiswi asli daerah yakni Public Relation dan Journalisme gaya hidup dimana mahasiswi mengikuti tren fashion dari artis korea,kemudian gaya hidup hedonis dimana mahasiswi menjadikan tayangan budaya korea menjadi salah satu hiburan dan cara menghabiskan waktu mereka untuk menikmati tayangan hasil budaya korea. 4) mahasiswi Program studi PPKn angkatan 2016 bentuk gaya hidupnya adalah gaya hidup hedonis, mereka menghabiskan waktu luang untuk lebih menikmati budaya populer korea mulai dari menonton,mendengarkan musik serta menggunakan media sosial. Lalu Iklan Gaya hidup, para mahasiswi tertarik membeli produk yang dibintangi oleh para artis idolanya.

5) bentuk gaya hidup Mahasiswi Program Studi PPKn angkatan 2017 adalah gaya hidup hedonis dan iklan gaya hidup karena mulai tertarik untuk mengonsumsi budaya populer korea (K-Pop

\section{Saran}

Berdasarkan Penelitian, maka saran yang akan disampaikan peneliti adalah sebagai berikut.

Bagi para mahasiswi yang menggemari budaya populer Korea (K-Pop), menggemari budaya ini sebagai salah satu hiburan memanglah tidak salah asalkan sewajarnya.Menggemari dengan selayaknya dan tidak melupakan kewajiban seorang mahasiswi.Para mahasiswi diharapkan mampu mengikuti hal-hal positif yang membangun para mahasiswi.Mahasiswi

\section{Paris Langkis}

Vol.1 Nomor 2, Maret 2021 
Program Studi PPKn diharapkan mampu mempertahankan kebudayaan asli Indonesia meski menggemari budaya populer Korea (K-Pop).

\section{DAFTAR PUSTAKA}

Aslamiyah, M. 2013. Identitas Diri Mahasiswa Penyuka Budaya Pop Korea di Malang.

Ida Ri'aeni, Suci, M., Pertiwi, M., \& Sugiarti, T. (2019). Pengaruh Budaya Korea (K-Pop) terhadap Remaja di Kota Cirebon. In Communications.

Kaparang, O. M. (2013). Analisa Gaya Hidup Remaja Dalam Mengimitasi Budaya Pop Korea Melalui Televisi. Journal "Acta Diurna".

Keesing, R. (2014). Teori-Teori Tentang Budaya. Antropologi Indonesia. https://doi.org/10.7454/ai.v0i52.3313

Ridaryanthi, M. (2014). Bentuk Budaya Populer dan Konstruksi perilaku Konsumen ... Jurnal Visi Komunikasi. https://doi.org/https://media.neliti.com/media/publications/142786ID-bentuk-budaya-populer-dan-konstruksi-per.pdf

https://kbbi.kemdikbud.go.id/entri/populer di akses pada 9 Mei, 2020 